\title{
AS ASSIMETRIAS DO SISTEMA MONETÁRIO E FINANCEIRO INTERNACIONAL *
}

\author{
Daniela Magalhães Prates
}

\begin{abstract}
RESUMO Este artigo pretende avançar na compreensão das causas da maior vulnerabilidade dos países “emergentes” às crises financeiras nos anos 90 a partir de uma abordagem heterodoxa. Argumenta-se que as assimetrias do sistema monetário e financeiro internacional contemporâneo contribuem para explicar essa maior vulnerabilidade, bem como a tendência ao endividamento em moeda estrangeira e à dolarização, fatores subjacentes à recorrência de crises gêmeas — cambiais e bancárias - nesses países.
\end{abstract}

Palavras-chave: crises financeiras; países emergentes; sistema monetário e financeiro internacional; centro-periferia; fluxos de capitais

Código JEL: F020; F310

\section{THE ASYMMETRIES OF THE INTERNATIONAL \\ MONETARY AND FINANCIAL}

ABSTRACT The purpose of this article is to develop an heterodox interpretation of the financial crises of the so called "emergent countries" occurred in the 90s. It argues that the asymmetries of the international monetary and financial system explain the greater vulnerability of these countries to those crises. Such asymmetries also give rise to two particularities that underlines their twin character (currency and bank crises) in the "emergent" countries: the dollarization and the indebtedness in foreign currencies.

Key words: financial crises; emergent countries; international monetary and financial system, center-periphery; capital flows

* Artigo recebido em 19 de agosto de 2004 e aprovado em 9 de março de 2005.

** Professora doutora do Instituto de Economia/Unicamp, e-mail: daniprates@uol.com.br 
Não estão na bibliografia

\section{INTRODUÇÃO}

A freqüência de crises financeiras ${ }^{1}$ aumentou de forma considerável nos anos 80 e 90, relativamente às décadas anteriores, tanto nos países centrais quanto nos emergentes. ${ }^{2}$ Contudo, no caso desses países, as crises cambiais foram mais recorrentes e as crises bancárias mais severas. Além disso, essas crises tenderam a se converter em crises cambiais, da mesma forma que essas últimas ameaçaram a estabilidade dos sistemas financeiros domésticos, ou seja, as crises tiveram, de forma geral, um caráter gêmeo (Eicheengreen e Bordo, 2002).

As sucessivas crises financeiras dos países emergentes na segunda metade da década de 1990 despertaram o interesse dos economistas do mainstream. ${ }^{3}$ Como reconheceram esses mesmos economistas, os modelos de crises cambiais desenvolvidos nos anos 80, conhecidos como modelos de primeira geração, ${ }^{4}$ se revelaram insuficientes para a compreensão desses eventos, que apresentaram características até então praticamente ignoradas pela literatura convencional, como imprevisibilidade e desvinculação com os fundamentos fiscais e monetários dos países.

Nesse contexto, os teóricos do mainstream passaram a introduzir nos seus modelos fatores externos aos países que têm caracterizado o sistema financeiro internacional contemporâneo, entre os quais os ataques especulativos auto-realizáveis e o comportamento de manada dos investidores estrangeiros. ${ }^{5}$ Contudo, nos novos modelos desenvolvidos (conhecidos como modelos de segunda e terceira gerações), os determinantes em última instância das crises continuam sendo os desequilíbrios internos aos países, gerados seja por distorções governamentais (isto é, fatores "extra mercado"), seja por falhas nos mercados financeiros (nacionais e/ou internacionais).

Simultaneamente, alguns autores heterodoxos também procuraram fornecer uma explicação para as crises financeiras dos países emergentes na se1996? gunda metade dos anos 90. Kregel (1999), seguindo a tradição de Keynes e Minsky, defende que essas crises são sistêmicas — não decorrendo de fatores extramercado ou das chamadas "falhas de mercado", como nos modelos convencionais - e foram geradas endogenamente a partir da absorção de intensos fluxos de capitais, que resultou na emergência de situações de fragilidade macroeconômica e financeira doméstica. O processo de fragilização não teria decorrido de políticas inconsistentes, mas da introdução de 
políticas voltadas para a obtenção ou manutenção da estabilidade macroeconômica e para a integração da economia no ambiente de globalização fi1996? nanceira. ${ }^{6}$ Além de Kregel (1999), Taylor (1998) e Eatwell e Taylor (2000) destacam, igualmente, o processo endógeno de deterioração da situação macroeconômica e financeira desses países a partir do ingresso dos fluxos de capitais. Todavia, essas análises privilegiam a dinâmica interna das crises, não explorando as causas da maior vulnerabilidade dos países emergentes às crises financeiras nesse ambiente.

Este artigo pretende avançar na compreensão dessa maior vulnerabilidade a partir de uma abordagem heterodoxa que se apóia nas contribuições de Keynes - que destacou a natureza monetária e a instabilidade intrínseca das economias capitalistas modernas - e de Prebisch - o qual enfatizou as assimetrias centro-periferia no âmbito do sistema capitalista mundial. Assim, o objeto do artigo não são as crises propriamente ditas, mas as condições da sua emergência.

Como as análises heterodoxas mencionadas acima, parte-se da hipótese de que as crises dos países emergentes constituíram mais uma manifestação da instabilidade sistêmica que tem caracterizado o sistema monetário e financeiro internacional desde o colapso de Bretton Woods. ${ }^{7}$ Os traços gerais desse sistema são apresentados na seção 1 . Na seção 2 procura-se desenvolver a hipótese central deste artigo, qual seja: a maior vulnerabilidade dos países emergentes às crises financeiras nos anos 90 esteve associada às assimetrias monetárias e financeiras desse sistema; ademais, essas assimetrias também contribuem para explicar seu caráter predominantemente gêmeo, destacado no início desta Introdução.

\section{O SISTEMA MONETÁRIO E FINANCEIRO INTERNACIONAL CONTEMPORÂNEO}

As características do sistema monetário internacional (SMI) em cada período da história são: a forma da moeda internacional; o regime de câmbio; e o grau de mobilidade dos capitais. Uma quarta característica fundamental, nem sempre ressaltada pela literatura, é a dimensão hierárquica desse sistema. Como salienta Miranda (1995, p. 187), "no âmbito de um sistema (ou não-sistema) monetário internacional (...) existe uma hierarquia de moedas 
que determina condições, potencialidades e graus de liberdade diferenciados para as economias nacionais". Essas características, por sua vez, moldam o perfil do sistema financeiro internacional em cada período - como destacou Keynes durante os debates que precederam a conferência de Bretton Woods (Keynes, 1980).

A moeda internacional deve desempenhar as funções da moeda nacional - meio de liquidação das transações e dos contratos, unidade de conta e reserva de valor - em âmbito internacional. Todavia, há uma diferença qualitativa entre essas duas formas de moeda, já que não existiu (até o momento atual) uma verdadeira moeda internacional (Guttman, 1993). Apesar das diferentes características dos sistemas monetários internacionais que se sucederam desde o século XIX, a solução prática para este dilema foi semelhante. A partir de um compromisso hierárquico entre os países centrais que reflete as relações de poder entre esses países, estabelece-se uma moedachave - em geral, a moeda do país hegemônico — e o regime cambial vigente. No entanto, esse compromisso tem um caráter contraditório, pois a moeda-chave é igualmente um ativo financeiro, em concorrência com as outras divisas (Brunhoff, 1996).

O SMI que emergiu após o colapso do acordo de Bretton Woods também se baseou nesse compromisso e, assim, numa divisa-chave, o dólar. Os demais traços desse sistema são: o regime de câmbio flutuante e a livre mobilidade de capitais. Esta seção dedicar-se-á às três dimensões do SMI sobre as quais se concentra a literatura - o papel do dólar como moeda-chave, o regime de câmbio flexível ou flutuante e a livre mobilidade de capitais - e ao perfil do sistema financeiro internacional contemporâneo. Já a sua dimensão hierárquica será tratada somente na seção 3, pois constitui um dos elementos centrais da hipótese central deste artigo que será desenvolvida nesta seção.

A posição do dólar como moeda-chave ancorou-se, após o colapso de Bretton Woods, no poder financeiro dos Estados Unidos, associado à importância das instituições financeiras americanas e à dimensão do seu mercado financeiro doméstico (Strange, 1986; Helleiner, 1994). A hegemonia financeira foi reforçada pelo choque de taxa de juros de 1979, que inaugurou a política do "dólar forte", bem como pela desregulamentação e/ou liberalização financeiras ${ }^{8}$ implementadas no final dos anos 70 , medidas que 
marcaram o que Tavares (1997) denominou "retomada da hegemonia americana". Retomada porque nos anos 70 observou-se um crescente questionamento da posição do dólar como moeda-chave do sistema, reflexo da fragilização da liderança tecnológica e comercial dos Estados Unidos, subjacente a essa posição no sistema de Bretton Woods.

É importante esclarecer o papel desempenhado pelo dólar nesse ambiente. Como destacam Tavares e Melin (1997), nesse sistema o dólar não desempenha mais a função de reserva de valor como um padrão monetário clássico, mas cumpre, principalmente, o papel de moeda financeira num sistema desregulado e sem paridades cambiais fixas.

A denominação em dólar das operações plurimonetárias (de securitização, ${ }^{9}$ arbitragem etc.) realizadas no mercado financeiro internacional cumpre três funções primordiais para os investidores globais: fornece liquidez instantânea em qualquer mercado; garante segurança nas operações de risco; e serve como unidade de conta da riqueza financeira virtual, presente e futura. Ou seja, o dólar passou a cumprir o papel de moeda financeira de origem pública, capaz de cumprir o papel de denominador comum da riqueza financeira global (Tavares e Melin, 1997). E os títulos da dívida pública americana consolidaram sua posição como um refúgio seguro nos momentos em que a confiança dos investidores globais é abalada (Belluzzo, 1997).

Além da sua transformação em moeda financeira, Teixeira (2000) e Serrano (2002) destacam uma segunda mudança fundamental na natureza do dólar, enquanto moeda-chave do sistema monetário e financeiro internacional, a qual estaria subjacente à concentração do poder em mãos dos Estados Unidos e ao desequilíbrio que caracteriza as relações internacionais contemporâneas. Segundo esses autores, a especificidade da situação atual em relação à estabelecida em Bretton Woods decorreria da natureza exclusivamente fiduciária do dólar, que deixou de estar vinculado a qualquer mercadoria real (ou seja, ao ouro). Essa natureza garantiria um grau de autonomia de política ainda maior para o país emissor da moeda-chave. Nesse contexto, a gestão da política monetária americana e, assim, as variações da taxa de juros básica do sistema, que influenciam decisivamente a direção dos fluxos internacionais de capitais, passariam a depender estreitamente do ciclo econômico doméstico americano. ${ }^{10}$ 
Simultaneamente, ao se libertar das "amarras" da conversibilidade em última instância ao ouro, os Estados Unidos puderam incorrer em déficits comerciais recorrentes, o que teria resultado em outra especificidade do sistema monetário interacional após Bretton Woods: o caráter devedor líquido do país emissor da moeda-chave. Esse caráter introduz novas fontes de instabilidade no sistema, pois a política monetária americana também está subordinada (mesmo que em menor grau) à necessidade de rolagem da dívida pública mobiliária interna e de sustentação do valor do dólar. As eventuais inconsistências entre os objetivos internos e externos dessa política resultam numa incerteza em relação à trajetória das taxas de juros e de câmbio americanas que, dada a sua posição central no sistema, se transmite aos demais países centrais e periféricos (Belluzzo, 1997).

Ao lado das características da moeda-chave contemporânea - sua natureza fiduciária e o caráter devedor líquido dos Estados Unidos -, essa incerteza decorre, igualmente, das demais características desse sistema mencionadas acima: o ambiente de livre mobilidade de capitais e o regime de câmbio flutuante.

Enquanto a consolidação desse ambiente esteve vinculada às decisões de política dos Estados Unidos com o objetivo de assegurar a supremacia do dólar no sistema monetário e financeiro internacional, ${ }^{11}$ sua emergência foi, por sua vez, o determinante em última instância do colapso do regime de paridades fixas de Bretton Woods, substituído por um regime de câmbio flutuante. Como destaca Eichengreen (1996), estas duas dimensões estão intrinsecamente vinculadas: a tendência de aumento da flexibilidade cambial no pós-guerra constitui uma conseqüência inevitável da crescente mobilidade de capitais. ${ }^{12}$

O regime de câmbio flutuante num contexto de livre mobilidade de capitais não implicou maior estabilidade das taxas de câmbio e eliminação dos desequilíbrios dos balanços de pagamento, como propagavam os monetaristas no final dos anos 60, mas uma extrema volatilidade das taxas de câmbio e de juros (Belluzzo,1995). A imprevisibilidade da evolução das taxas de câmbio estimulou a especulação nos mercados de câmbio e os fluxos de capitais de curto prazo, que acentuaram ainda mais a volatilidade dos mercados de divisas. ${ }^{13}$

Uma das conseqüências desse contexto de incerteza estrutural em relação à trajetória dos preços-chave é a maior preferência pela liquidez dos 
agentes que atuam no mercado monetário e financeiro internacional. Mas esta não decorre somente das características do padrão dólar "flexível, financeiro e fiduciário" sintetizadas acima, mas também da dinâmica do sistema financeiro internacional contemporâneo, ditada pela globalização financeira e pela predominância das chamadas finanças de mercado. A seguir detalha-se esta dinâmica.

A globalização financeira, que se consolidou ao longo dos anos 80 , constituiu um desdobramento das tendências já presentes no sistema financeiro internacional a partir da emergência do euromercado e da adoção do sistema de taxas de câmbio flutuantes. O conjunto de transformações financeiras subjacente a esse processo - a liberalização e/ou desregulamentação financeiras, a securitização das dívidas, a institucionalização das poupanças e a proliferação das inovações financeiras - surgiu nos Estados Unidos e passou a contaminar os demais países centrais, em ritmos e intensidade diferenciados e, sobretudo, o sistema financeiro internacional, exatamente em função da posição do dólar como moeda-chave e das políticas de desregulamentação e abertura financeiras lideradas por esse país.

A despeito das especificidades nacionais (em termos de timing e velocidade), os processos de liberalização e desregulamentação financeiras tiveram um importante desdobramento na maioria dos países centrais, destacado por Aglietta (1995): o aumento da importância dos mercados de capitais vis-à-vis o mercado de crédito bancário e, conseqüentemente, o aprofundamento das finanças de mercado, o qual alterou profundamente $\mathrm{o}$ comportamento dos agentes - famílias, empresas e instituições financeiras —, cuja lógica de investimento adquiriu um caráter cada vez mais especulativo.

Como ressaltou Keynes (1936), num ambiente caracterizado pela predominância de mercados financeiros organizados e líquidos, a lógica empresarial torna-se subordinada, enquanto a especulativa revela-se dominante. Nesse contexto, os investimentos não são mais realizados pela sua capacidade de produzir um fluxo de rendimentos que, capitalizados à taxa de juros corrente, superem o valor inicial desembolsado, mas em função do ganho de capital que podem gerar, a partir da expectativa de variação do valor de mercado do ativo no curto prazo. Em outras palavras, os agentes, nas suas decisões de alocação da riqueza, passam a ser guiados pela lógica especulativa, na medida em que procuram "prever a psicologia do mercado", ou seja, 
a "opinião média do mercado", a qual determina os preços dos ativos financeiros. ${ }^{14}$

A dominância da esfera financeira de valorização sobre a produtiva no capitalismo contemporâneo tem sido ressaltada por vários autores heterodoxos, como Chesnais (1997), Orléan (1999) e Braga (1997). De acordo com esse último autor, essa dominância reflete a emergência de um novo padrão de gestão da riqueza denominado "financeirização". Neste padrão, que surgiu nos Estados Unidos e se difundiu, progressivamente, nos demais países centrais e no sistema financeiro internacional, a especulação tornouse sistêmica e não apenas um momento dos ciclos e tem caracterizado as ações de todos os agentes econômicos relevantes. ${ }^{15}$

No âmbito nacional, o predomínio da acumulação financeira sobre a produtiva resultou numa nova dinâmica macroeconômica nos países centrais, cuja expressão principal é o denominado ciclo de ativos. ${ }^{16}$ Contudo, essa nova forma de gestão da riqueza não ficou circunscrita às fronteiras nacionais. As decisões de alocação da riqueza financeira dos agentes - investidores institucionais, que gerem as poupanças das famílias, grandes bancos e empresas transnacionais - ditam, igualmente, a direção e as características das diversas modalidades de fluxos de capitais, que se descolaram dos fluxos de comércio e produção mundiais. Ou seja, a lógica especulativa entranhou-se, profundamente, no comportamento do conjunto de agentes econômicos e passou a condicionar suas decisões de consumo, poupança, investimento, aplicação financeira, endividamento e concessão de crédito, em âmbito doméstico e internacional.

A lógica especulativa imprime um perfil volátil aos fluxos de capitais de forma geral, o que não implica inexistência de uma diferenciação em termos de volatilidade entre as várias modalidades de fluxos. Testes estatísticos realizados por Turner (1991) sugerem o seguinte ranking: investimento externo direto (IED), investimento de portfólio e empréstimos de curto prazo.

A extrema volatilidade dos preços-chave (taxas de câmbio e de juros) que tem caracterizado o sistema monetário internacional após o colapso de Bretton Woods - contribuiu, igualmente, para a generalização da lógica especulativa. Nesse contexto, a formação de expectativas sobre a evolução desses preços tornou-se "uma necessidade quase imperativa para os agentes na condução normal de suas atividades" (Farhi, 1999, p. 103). Ou seja, a an- 
tecipação "da psicologia do mercado" passou a guiar a ação de todos os agentes econômicos relevantes que atuam em âmbito internacional, contaminando as diversas modalidades de fluxos de capitais.

A nova forma de atuação das empresas transnacionais, ditada pela "financeirização", resultou no aumento da importância dos fluxos de IED associados a fusões e aquisições de empresas, que constituem operações patrimoniais de valorização da riqueza, inerentemente mais voláteis que o chamado greenfield investment (implantação de novas plantas). Ademais, no contexto da globalização financeira, mesmo o greenfield investment pode gerar pressões sobre o mercado de câmbio dos países receptores (Kregel, 1996). Isto porque as inovações financeiras recentes - com destaque para os derivativos - , além de contribuírem para a diluição das fronteiras entre os investimentos de curto e longo prazos, possibilitam a realização de operações de hedge contra os riscos cambiais associados aos IED, as quais também implicam fluxos financeiros de curto prazo.

Já os fluxos de crédito bancário, cuja importância não deve ser negligenciada, passaram a ter um perfil cada vez mais de curto prazo. No ambiente de globalização financeira, esses fluxos revelam-se fundamentais para a estruturação não somente das operações de hedge mencionadas acima, mas também de posições de risco em diferentes moedas (ou ativos denominados em moedas distintas), envolvendo derivativos. Apesar da existência de diferentes graus de liberdade de atuação nesses sistemas (dependendo dos limites de exposição em moeda estrangeira e da autorização ou não de empréstimos nessa moeda), os bancos têm a capacidade de efetuar a cobertura contra o risco cambial de qualquer tipo de transação (comercial, financeira, com derivativos), mas podem, igualmente, optar por uma posição descasada diante da trajetória esperada das taxas de juros e de câmbio, o que reflete uma atitude especulativa (Carneiro, 1999).

Já os investimentos de portfólio - compras e vendas de ações e títulos de renda fixa, além das fronteiras - , que constituem os fluxos de capitais característicos do sistema financeiro internacional globalizado, têm uma natureza inerentemente especulativa, pois são motivados por ganhos de curto prazo e não por considerações de longo prazo, que resultam, por sua vez, em intensas oscilações dos preços dos ativos e do câmbio. O aumento da importância dessa modalidade de fluxo a partir dos anos 80 esteve dire- 
tamente associado à atuação dos investidores institucionais, predominantemente americanos e ingleses, que "procuram otimizar globalmente seus rendimentos financeiros líquidos mediante operações que visam antecipar as variações dos preços dos ativos nos diferentes mercados" (Cintra, 1997).

Contudo, a lógica especulativa dos fluxos de portfólio não decorre somente da atuação dos fundos de investimento e dos fundos de pensão, cujos gestores são dominados por uma lógica patrimonialista, com ênfase na performance do portfólio. ${ }^{17}$ Ao lado desses investidores institucionais, os bancos e as grandes empresas são agentes igualmente protagonistas do mercado internacional de capitais.

Os bancos tiveram um papel fundamental na expansão desse mercado: além de terem securitizado uma parte significativa de seus empréstimos no contexto da crise da dívida externa dos anos 80, essas instituições constituem as principais responsáveis pela transferência de recursos entre agentes deficitários e superavitários. Como esclarece Freitas (1997), a importância crescente dos mercados de capitais e o avanço da securitização não significaram uma desintermediação financeira, mas uma nova forma de intermediação financeira, caracterizada pela predominância dos ativos financeiros negociáveis tanto no passivo quanto no ativo dos bancos.

No mercado internacional de capitais, os bancos atuam de forma direta - comprando e vendendo securities, administrando as carteiras de grandes investidores, estruturando operações com derivativos financeiros - e indireta, mediante a concessão de empréstimos aos investidores e intermediários financeiros que atuam nesse mercado (Guttmann, 1996). Essa atuação indireta é fundamental para garantir a liquidez dos mercados de ativos, já que os bancos comerciais ou universais funcionam como market makers e são os únicos que têm acesso ao meio de pagamento em última instância, a moeda emitida pelo Banco Central (Aglietta, 1995).

As empresas transnacionais também se tornaram importantes atores do mercado internacional de capitais (Serfati, 1996). Essas empresas passaram a deter um estoque significativo de moedas conversíveis, derivativos e títulos estrangeiros. Como ressalta Braga (1997), a liquidez que elas manejam tornou-se estratégica - o que significa a posse permanente de estoques de moedas, quase-moedas e ativos financeiros domésticos e estrangeiros em lugar da preferência pela liquidez conjuntural, que se revela fundamen- 
tal não somente para viabilizar as operações de hedge num contexto de instabilidade dos preços-chave, mas também para a valorização do capital na esfera financeira.

Em suma, dado o contexto de assimetria de informação e poder, opiniões divergentes, incerteza e preferência elevada pela liquidez que caracteriza os mercados financeiros contemporâneos, os agentes protagonistas nesses mercados (fundos mútuos e de pensão, grandes bancos e tesouraria das grandes empresas) são obrigados a formular estratégias com base numa avaliação convencionada sobre o comportamento dos preços e são os formadores de convenções. Suas estratégias são mimetizadas pelos demais investidores de menor porte e informação, implicando a formação de bolhas especulativas e posteriores colapsos de preços (Coutinho e Belluzzo, 1996). Nos termos de Orléan (1999), as ações dos agentes são guiadas pela racionalidade "auto-referencial", que resulta na predominância de comportamentos miméticos ou de manada e numa extrema volatilidade dos fluxos recentes de capitais, que afeta especialmente os países emergentes, como se destacará na próxima seção.

\section{AS ASSIMETRIAS DO SISTEMA MONETÁRIO E FINANCEIRO}

\section{INTERNACIONAL E AS CRISES FINANCEIRAS DOS PAÍSES EMERGENTES}

Esta seção apresenta e desenvolve a seguinte hipótese: a maior vulnerabilidade dos países emergentes às crises financeiras nos anos 90 esteve associada às assimetrias monetárias e financeiras do sistema monetário e financeiro internacional contemporâneo, ${ }^{18}$ as quais explicariam sua maior suscetibilidade ao perfil volátil dos fluxos recentes de capitais. Essas assimetrias contribuem, igualmente, para explicar a maior incidência das chamadas crises gêmeas nesses países, pois estariam subjacentes à tendência ao endividamento em moeda estrangeira e à dolarização, que resultam nos feedbacks recíprocos entre crises cambiais e bancárias.

A assimetria monetária diz respeito à hierarquia de moedas em âmbito internacional. Como já mencionado na seção precedente, a dimensão hierárquica do sistema monetário internacional não é exclusiva do sistema contemporâneo. Desde o padrão ouro, existe uma hierarquia de moedas no âmbito internacional. ${ }^{19}$ Todavia, pretende-se mostrar como essa hierarquia 
pode se revelar ainda mais perversa no ambiente atual, dadas as características do sistema monetário e financeiro internacional contemporâneo, sintetizadas na seção 1 .

No sistema atual, o dólar constitui o núcleo do sistema hierarquizado ou seja, é a moeda-chave - a partir do qual se posicionam, de forma também hierarquizada, as outras moedas: em primeiro lugar, as moedas conversíveis, emitidas pelos demais países centrais, e, em segundo lugar, mais distantes do núcleo, as moedas não-conversíveis, emitidas pelos países emergentes (Carneiro, 1999).

O conceito de conversibilidade refere-se à aceitação das moedas nacionais como meio de pagamento, unidade de conta e de denominação dos contratos, e ativo de reserva no sistema monetário internacional. Em outras palavras, uma moeda nacional é totalmente conversível se é capaz de desempenhar no âmbito internacional as três funções da moeda. Contudo, existem diferentes graus de conversibilidade.

$\mathrm{Na}$ hierarquia de moedas, somente o dólar, enquanto moeda-chave, desempenha integralmente essas três funções e, assim, tem o maior grau de conversibilidade. O dólar é a moeda utilizada, preponderantemente, nas transações monetárias (meio de troca) e financeiras (unidade de denominação dos contratos), bem como é o ativo mais líquido e seguro e, assim, mais desejado pelos agentes como ativo de reserva e "receptáculo" da incerteza, estruturalmente mais elevada e volátil no contexto atual tanto em função da instabilidade do sistema monetário internacional após o colapso de Bretton Woods como da lógica especulativa das finanças globalizadas.

As moedas dos demais países centrais também são utilizadas como meio de denominação dos contratos no âmbito internacional e são demandadas, de forma secundária, como ativo de reserva nos portfólios dos investidores estrangeiros. Já as moedas dos países periféricos participantes do sistema ou seja, os emergentes - não são conversíveis. Ao contrário dos países centrais, esses países, de forma geral, não são capazes de emitir dívida externa denominada na própria moeda. ${ }^{20}$

Em relação à função reserva de valor, suas respectivas moedas não cumprem o papel de "receptáculo" da incerteza no âmbito mundial. A principal manifestação dessa não-conversibilidade, especificamente no que se refere à função reserva de valor, são os diferentes prêmios de risco atribuídos às 
moedas, que decorrem da regra de formação das taxas de juros no sistema monetário e financeiro internacional, desfavorável para os países não emissores da divisa-chave e, sobretudo, para os emergentes.

Como explica Carneiro (1999), a taxa de juros do dólar, que constitui a taxa básica do sistema, tende a ser a menor de todas, pois remunera a moeda-chave, considerada a mais segura e mais líquida pelos detentores de capital. As taxas de juros fora do núcleo correspondem sempre à taxa de juros do dólar acrescida do risco país. Os países mais distantes do núcleo - ou seja, os emergentes - têm as taxas de juros mais elevadas, pois suas moedas são consideradas as menos seguras e, assim, os investidores exigem um prêmio maior para retê-las. Visto o problema de outro ângulo, os proprietários de capitais na periferia aceitam taxas de remuneração menores para aplicar nas moedas conversíveis.

Dado o ambiente de livre mobilidade de capitais, se os países emergentes fixam taxas de juros internas abaixo da taxa fixada pelo mercado, eles não somente deixam de atrair capitais, como provocam uma fuga dos capitais locais. Já para os países emissores de moedas conversíveis existe a possibilidade de escapar dessa regra dado o fluxo permanente de capitais produtivos e financeiros. Nesses países, a fixação da taxa de juros interna abaixo da taxa de mercado resulta na saída de capitais e na desvalorização da taxa, de câmbio. Contudo, a partir de um determinado patamar dessa taxa passa a ser atraente o retorno dos capitais, diante dos baixos preços dos ativos produtivos e financeiros por causa da moeda desvalorizada. No caso dos países emergentes, essa alternativa não se coloca, pois não há um piso para a desvalorização da taxa de câmbio em razão da inexistência daquele fluxo (Carneiro, 1999). A inexistência desse fluxo decorre, por sua vez, da assimetria financeira, como se destacará a seguir.

Assim, essa regra de formação da taxa de juros resulta em diferentes graus de autonomia de política dos países pertencentes ao sistema. Em outras palavras, a assimetria monetária implica assimetria macroeconômica.

Da mesma forma que nos sistemas monetários internacionais precedentes (padrão libra-ouro e Bretton Woods), baseados igualmente numa moeda nacional como moeda-chave (libra e dólar, respectivamente), o país emissor da moeda-chave tem maior grau de autonomia de política. Contudo, no sistema atual, essa autonomia é ainda maior graças ao caráter fidu- 
ciário dessa moeda, que permite aos Estados Unidos vincular, estreitamente, a gestão da sua política monetária ao ciclo econômico doméstico (Teixeira, 2000). No espectro oposto estão os países emergentes que, por serem emissores de moedas não conversíveis, têm menor grau de autonomia de política.

Além de não terem condições de escapar da regra de formação da taxa de juros do sistema em períodos de normalidade, dado o ambiente de livre mobilidade de capitais, em períodos de abundância ou escassez de recursos esses países, de forma geral, não têm graus de liberdade para adotar políticas anticíclicas que atenuariam os impactos dos fluxos de capitais sobre o desempenho econômico doméstico. Já os países centrais têm um maior grau de autonomia de política econômica (obviamente menor que o país emissor da moeda-chave) exatamente em função da natureza conversível de suas moedas, que possibilita a utilização da política monetária para manejar o ciclo econômico doméstico. Nos termos de Ocampo (2001), o centro tem maior autonomia de política, sendo assim policy making, e a periferia é essencialmente policy taking.

Contudo, uma ressalva é necessária. A despeito da tendência da globalização financeira, os países emergentes diferenciaram-se em relação ao grau de abertura financeira. Em princípio, nos países que mantiveram controles sobre os fluxos de capitais, a autonomia de política foi maior e vice-versa. Este artigo, todavia, não tratará da relação entre autonomia de política macroeconômica e grau de abertura financeira, pois esta contribui para explicar diferenças na vulnerabilidade externa dos países emergentes, enquanto se pretende, aqui, destacar as especificidades do grupo "países emergentes", vis-à-vis os países centrais, que os tornaram mais suscetíveis às crises financeiras nos anos 90 .

À assimetria do sistema monetário internacional sobrepõe-se a assimetria do sistema financeiro internacional, que diz respeito a dois fatores: em primeiro lugar, aos determinantes dos fluxos de capitais direcionados para os países emergentes; em segundo lugar, à dimensão relativa desses fluxos.

O volume e a direção desses fluxos são determinados, principalmente, por fatores externos a esses países, tanto conjunturais - a fase do ciclo econômico e o patamar das taxas de juros do país emissor da moeda-chave e, em menor medida, dos demais países centrais, que determinam o estado de 
liquidez dos mercados financeiros internacionais - quanto estruturais a nova dinâmica financeira internacional. ${ }^{21}$ Como destaca Ocampo (2001), enquanto o centro gera os choques globais (em termos de fluxos de capitais, em termos de troca etc.), sendo business-cycle makers, os países em desenvolvimento (a periferia) são business-cycle takers.

É importante destacar que essa característica não é exclusiva dos fluxos recentes de capitais. Historicamente, a dinâmica do mercado financeiro internacional determinou as características dos fluxos de capitais para a periferia, enquanto que a dinâmica econômica - crescimento versus recessão - nos países centrais condicionou o seu volume (Baer, 1995). Contudo, essa assimetria tornou-se ainda mais perversa no contexto atual, dado o perfil volátil e especulativo desses fluxos, que dependem das avaliações e das decisões de investimento dos agentes residentes nesses países, que se guiam por critérios financeiros e especulativos e exprimem um grau elevado de preferência pela liquidez.

Ademais, a dinâmica atual dos capitais produtivos, cujos espaços privilegiados de valorização encontram-se em seus países de origem (ou seja, nos países centrais), contribui para acentuar a assimetria financeira. Como ressaltado na seção 1, os fluxos de investimento direto externo também foram contaminados pela lógica especulativa e passaram a exercer pressões sobre os mercados de câmbio dos países receptores, associadas às operações de hedge realizadas pelas empresas multinacionais, as quais são ainda mais intensas no caso dos países periféricos, pois os investimentos direcionados para esses países embutem um maior risco cambial por causa da assimetria monetária.

A segunda dimensão da assimetria financeira diz respeito à forma particular de inserção dos países emergentes nos fluxos financeiros internacionais. Por um lado, apesar do crescimento em termos absolutos dos fluxos direcionados para esses países nos anos 90, uma proporção ainda marginal dos recursos detidos pelos investidores globais é alocada nos "mercados emergentes". ${ }^{22}$ Por outro lado, os títulos emitidos pelos países emergentes, principalmente daqueles com maior prêmio de risco, classificados como "sem grau de investimento" pelas agências de classificação de risco de crédito, integram um submercado mais amplo, o de papéis de alta rentabilidade, o qual tem uma dinâmica ainda mais volátil. ${ }^{23}$ 
Mesmo no âmbito dos países emergentes, não houve uma pulverização das aplicações nos anos 90. Como os mercados de securities e de ações desses países são menos líquidos, existe uma tendência de concentração dos investimentos nos mercados maiores e nas emissões que envolvem uma maior captação de recursos. Em outras palavras, os fluxos financeiros direcionados para a "periferia" são seletivos em vários aspectos, selecionando não somente os países, mas também os agentes. Como enfatiza Chesnais (1997), a globalização financeira é, além de excludente — penalizando fortemente os países periféricos não inseridos no processo de globalização, caso dos africanos - , hierarquizada, integrando os sistemas financeiros nacionais de forma desigual, imperfeita e incompleta.

Após essa caracterização geral das assimetrias do sistema monetário e financeiro internacional globalizado, é fundamental explicitar as relações entre essas assimetrias, cujas dimensões (monetária e financeira) se autoreforçam, e a maior vulnerabilidade dos países emergentes às crises financeiras contemporâneas.

A volatilidade inerente aos fluxos recentes de capitais afeta, sobretudo, os países emergentes, pois esses fluxos são determinados, em última instância, por uma dinâmica exógena a esses países, especificamente, o ciclo econômico e a política monetária dos países centrais e as decisões de aplicação e resgate dos investidores globais (uma das dimensões da assimetria financeira). Nos momentos de reversão do ciclo, mudanças na política monetária no centro ou aumento da preferência pela liquidez, as moedas e os ativos financeiros "emergentes", por não serem detidos como reserva de valor no âmbito internacional — reflexo da assimetria monetária —, são os primeiros a serem vendidos por esses investidores nos movimentos recorrentes de fuga para a qualidade (ou seja, para o dólar e/ou os títulos da dívida pública americana).

A recorrência desses movimentos está associada, igualmente, à gestão da política monetária do país emissor da moeda-chave, os Estados Unidos, cuja autonomia de política é ainda maior em razão da natureza fiduciária do dólar no sistema monetário internacional contemporâneo. A postura atual desse país afeta perversamente, sobretudo, os países emergentes. Por um lado, os choques financeiros, associados às mudanças nessa gestão, atingem, inicialmente e principalmente, suas moedas e ativos não conversíveis. 
Por outro lado, esses países têm um raio de manobra pequeno para adotar políticas anticíclicas (o qual dependerá do seu grau de abertura financeira), as quais atenuariam as variações do ciclo econômico doméstico associadas aos fluxos de capitais e, assim, a sua vulnerabilidade à reversão desses fluxos $\mathrm{e}$ às crises financeiras recentes.

A dimensão da assimetria monetária, relativa à função de unidade de denominação dos contratos, acentua igualmente a vulnerabilidade dos países emergentes às crises financeiras contemporâneas. A principal conseqüência dessa dimensão é a incapacidade desses países de emitirem, em volumes significativos, dívida nos mercados internacionais denominada na própria moeda, como destacado acima. Como esses países são historicamente dependentes de fontes de financiamento externas, a situação financeira dos devedores domésticos - e, com isso, a sua capacidade de honrar os compromissos externos - torna-se totalmente vinculada às variações das respectivas taxas de câmbio, potencialmente maiores no contexto atual por causa da volatilidade dos fluxos recentes de capitais. Ademais, como a maior parte da dívida externa desses agentes é denominada na moeda-chave (ou seja, em dólar), mudanças nas taxas de câmbio e de juros dessa moeda, associadas à gestão monetária americana, têm um impacto imediato sobre o valor dessa dívida, pois, como destaca Shulmeister (2000), o dólar desempenha a função de unidade de conta dos ativos internacionais.

A segunda dimensão da assimetria financeira - o fato de uma proporção marginal dos fluxos ser alocada nos "mercados emergentes" - contribui, igualmente, para a maior incidência dos choques financeiros, intrínsecos ao sistema monetário e financeiro internacional contemporâneo, nos países emergentes. Isto porque, se, de forma geral, o grau de instabilidade das aplicações é maior no caso dos ativos estrangeiros em relação aos nacionais (Plihon, 1996), no caso dos ativos "emergentes" - e, especialmente, daqueles classificados como "sem grau de investimento" - essa instabilidade é ainda maior, dados os impactos igualmente marginais da venda desses ativos sobre a rentabilidade dos portfólios globais, pela sua natureza residual.

Todavia, a despeito da natureza residual dos fluxos de capitais direcionados para os países emergentes, os efeitos potencialmente instabilizadores desses fluxos sobre os mercados de câmbio e de capitais domésticos são sig- 
nificativos, uma vez que, em relação ao tamanho desses mercados, o volume alocado pelos investidores globais não é marginal (Akyüz e Cornford, 1999). Pelo contrário, "a integração financeira internacional é uma integração entre parceiros desiguais” (Studart, 2003).

$\mathrm{Na}$ realidade, ao mesmo tempo em que acentuou a volatilidade estrutural dos mercados secundários dos países emergentes - associada à sua pequena dimensão, forte concentração e escassez de papéis de boa qualidade e líquidos —, a abertura externa não se traduziu em aprofundamento e maior dinamismo dos mercados primários, que permanecem como uma fonte de recursos marginal para a maioria das empresas domésticas. Como ressaltam Freitas e Prates (2003), em termos do desenvolvimento desses mercados, tanto os países asiáticos como os latino-americanos padecem do mesmo mal: mercados estreitos e altamente especulativos. ${ }^{24}$

No caso dos mercados de títulos de renda fixa, sua volatilidade é potencialmente mais intensa do que a apresentada pelas bolsas de valores, uma vez que sua dimensão é ainda menor, sendo esses mercados, de forma geral, dominados pelo segmento de títulos públicos. Assim, vendas por parte dos investidores estrangeiros reduzem significativamente os preços dos títulos, com potenciais repercussões sobre outros segmentos do mercado financeiro (Studart, 2003). Ademais, uma vez que em vários países emergentes esses mercados são totalmente ou parcialmente dolarizados (os títulos possuem cláusula de correção cambial), os feedbacks potenciais entre os mercados de títulos de renda fixa e de câmbio são mais acentuados, pois uma desvalorização cambial provocada pela reversão dos fluxos contamina o preço dos títulos, afetando a situação financeira dos devedores domésticos (GriffithJones, 1995).

Essa tendência à dolarização, que atinge diversos segmentos dos mercados financeiros emergentes, além do mercado de títulos de renda fixa, constitui uma característica adicional desses mercados que aumenta a vulnerabilidade dos países emergentes às crises gêmeas, pois acentua os feedbacks entre fragilidade cambial e bancária, associados igualmente ao endividamento externo em moeda estrangeira.

Essa tendência não decorre somente do passado inflacionário desses países, mas também da não-conversibilidade das moedas periféricas, que "contamina" o funcionamento dos sistemas financeiros domésticos. Na maioria 
dos casos, além dos investidores estrangeiros, os próprios residentes não aceitam deter ativos denominados em moeda doméstica, não conversível, ou exigem elevados prêmios de risco para detê-los. Da mesma forma, os bancos locais, que obtêm funding no mercado financeiro internacional em moeda estrangeira, em geral os repassam internamente na mesma moeda de captação ou com indexação cambial, para evitar o descasamento de moeda.

\section{CONSIDERAÇÕES FINAIS}

Este artigo procurou avançar na compreensão da maior vulnerabilidade dos países emergentes às crises financeiras nos anos 90 a partir de uma abordagem heterodoxa. Defendeu-se a hipótese de que essa maior vulnerabilidade decorreu das assimetrias monetárias e financeiras desse sistema, que têm uma natureza centro-periferia.

Foram destacados quatro importantes desdobramentos da assimetria monetária que contribuíram para essa maior vulnerabilidade. Em primeiro lugar, as moedas "periféricas”, por não desempenharem a função de reserva de valor, não são capazes de cumprir o papel de "receptáculo" da incerteza no âmbito mundial, estruturalmente mais elevada pelas características deste sistema. Pelo contrário, essas moedas são os primeiros alvos dos movimentos de fuga para a qualidade dos investidores globais, nos momentos de aumento da preferência pela liquidez. Uma manifestação adicional dessa incapacidade são os prêmios de risco mais elevados atribuídos a essas moedas, que contaminam as taxas de juros domésticas.

Em segundo lugar, esses países, historicamente dependentes de fontes de financiamento externas, de forma geral não são capazes de emitir dívida externa denominada na própria moeda. Com isso, a capacidade dos devedores domésticos de honrar os compromissos externos torna-se totalmente vinculada às variações das respectivas taxas de câmbio, potencialmente maiores no contexto atual em função da volatilidade dos fluxos recentes de capitais. Ademais, como a maior parte da dívida externa desses agentes é denominada na moeda-chave (ou seja, em dólar), mudanças nas taxas de câmbio e de juros dessa moeda associadas à gestão da política monetária americana - cujo grau de autonomia é praticamente total, dada a natureza 
fiduciária do dólar após o colapso de Bretton Woods — têm um impacto imediato sobre o valor dessa dívida.

O terceiro desdobramento da não-conversibilidade das suas moedas é o menor grau de autonomia de política dos países emergentes. Finalmente, a não-conversibilidade também "contamina" o funcionamento dos sistemas financeiros domésticos. Mais especificamente, é uma das causas da tendência de dolarização desses sistemas, pois, em muitos países, além dos investidores estrangeiros, os próprios investidores residentes não aceitam deter ativos denominados em moeda doméstica, não conversível, ou exigem elevados prêmios de risco para fazê-lo. Adicionalmente, os bancos residentes, que captam recursos no mercado financeiro internacional, os repassam internamente na mesma moeda de captação ou com indexação cambial, para evitar o descasamento de moeda em seus balanços.

Já a assimetria financeira tem duas dimensões. A primeira refere-se aos determinantes dos fluxos de capitais direcionados para os países emergentes. Esses fluxos dependem, em última instância, de uma dinâmica exógena a esses países, que estão permanentemente vulneráveis à sua reversão. A segunda dimensão da assimetria financeira diz respeito à inserção marginal dos países emergentes nos fluxos de capitais globais, que também contribui para a sua maior vulnerabilidade aos choques financeiros, intrínsecos ao sistema monetário e financeiro internacional contemporâneo, uma vez que a venda das moedas e dos ativos financeiros emitidos por esses países pelos investidores globais tem efeitos igualmente marginais sobre a rentabilidade dos seus portfólios. Em contrapartida, os efeitos potencialmente instabilizadores dos fluxos de capitais sobre os mercados de câmbio e de capitais emergentes são significativos, pois, relativamente à dimensão desses mercados, esses fluxos não são marginais.

Em suma, as assimetrias monetária e financeira, que são relacionadas e imbricadas, contribuem para explicar a maior vulnerabilidade dos países emergentes à volatilidade intrínseca aos fluxos recentes de capitais, bem como a tendência ao endividamento em moeda estrangeira e à dolarização, que resultam no descasamento de moedas e nos feedbacks recíprocos entre crises cambiais e bancárias, subjacente ao caráter predominantemente gêmeo das crises financeiras nesses países. 


\section{NOTAS}

1. Entende-se por crise financeira qualquer crise que atinja um ou vários segmentos dos mercados financeiros, envolvendo assim crises cambiais, bancárias, financeiras internas e gêmeas.

2. Neste artigo, o termo "países emergentes" refere-se aos países periféricos capitalistas que receberam a maior parte dos fluxos de capitais provenientes dos países centrais nos anos 90 .

3. Neste artigo, os termos mainstream e literatura convencional são utilizados como sinônimos e adota-se a definição de mainstream economics de Colander, Holt e Rosser (2003). De acordo com esses autores, este termo refere-se às idéias que a elite da profissão - os economistas líderes dos principais centros de graduação em economia — consideram aceitáveis, constituindo, assim, um termo mais amplo que ortodoxia - que consiste na escola de pensamento dominante num determinado período histórico (no contexto atual, a economia neoclássica). No âmbito do mainstream, novas idéias e abordagens - que não se enquadram na ortodoxia — podem ser aceitas, desde que sejam passíveis de modelagem. Já o termo heterodoxia definir-se-ia mais pelo que ele não é (pela rejeição à ortodoxia) do que pelo que ele é, dada a diversidade de escolas heterodoxas. E, mesmo que membros da heterodoxia compartilhem com economistas do mainstream visões semelhantes sobre limitações da ortodoxia, os heterodoxos não se enquadrariam no mainstream em razão da modelagem utilizada e/ou das hipóteses assumidas nos modelos.

4. O modelo canônico de primeira geração desenvolvido por Krugman (1979) sustenta que as crises cambiais são o resultado previsível de ataques especulativos inevitáveis, que resultam da resposta racional dos agentes privados a uma inconsistência de política econômica, decorrente da combinação de um regime de câmbio fixo com uma política fiscal expansionista financiada por emissão monetária.

5. Alguns economistas de orientação heterodoxa já enfatizavam o papel potencialmente instabilizador desses fatores antes da eclosão das crises. Ver, por exemplo, Akyüz (1992) e Felix (1994).

6. A globalização financeira refere-se à eliminação das barreiras internas entre os diferentes segmentos dos mercados financeiros, somada à interpenetração dos mercados monetários e financeiros nacionais e sua integração aos mercados globalizados (Chesnais, 1996).

7. Essa visão também é defendida pela Unctad (ver Unctad, 1998). Miranda (1998) chega a uma conclusão semelhante em sua análise sobre a crise asiática, mas enfatiza uma das dimensões dessa instabilidade: a inexistência de um padrão monetário internacional estável.

8. A desregulamentação e/ou liberalização monetária e financeira refere-se à diminuição dos controles governamentais sobre os mercados monetários e financeiros. Esses termos são, usualmente, utilizados como sinônimos na literatura.

9. A securitização refere-se à transformação de ativos não negociáveis (empréstimos bancários) em ativos negociáveis (títulos) e à proliferação de diversas modalidades de títulos ao portador emitidos por empresas, instituições financeiras e governos. 
10. Como destacam Medeiros e Serrano (1999), as condições geopolíticas (ou seja, o fim da Guerra Fria e o colapso da União Soviética) também contribuíram para o maior grau de autonomia de política do país emissor da moeda-chave.

11. Strange (1986) enfatiza que dois tipos de decisões de política foram essenciais para o surgimento e a consolidação desse ambiente: as decisões positivas e as negativas que se referem, respectivamente, às intervenções mediante regras ou recursos financeiros para influenciar ou restringir os mercados e à não-interferência dos governos nos mercados.

12. Eichengreen (1996) ressalta que essa mobilidade somente é compatível com um regime cambial alternativo ao flutuante (câmbio fixo ou administrado) se a autonomia da política econômica doméstica for utilizada como variável de ajuste, situação que prevaleceu durante o padrão libra-ouro.

13. Esse ambiente de incerteza estrutural em relação à evolução dos preços-chave está na origem do mercado de derivativos financeiros. Esses instrumentos financeiros (contratos futuros e a termo, opções, swaps etc.), referenciados a um ativo subjacente - taxas de câmbio, taxas de juros, etc —, surgiram com o objetivo de fornecer hedge contra as variações desses ativos, mas também expandiram o espaço para a especulação nos mercados financeiros, dado o seu poder de alavancagem. Para uma análise desses instrumentos, ver Farhi (1998).

14. Na abordagem keynesiana, os preços dos ativos financeiros não refletem os fundamentos, mas as convenções prevalecentes nos mercados financeiros, ou seja, a "opinião média do mercado" (Orléan, 1999).

15. Esse novo padrão de gestão da riqueza não "contaminou” da mesma forma todos os países. Seu grau de difusão está diretamente associado ao grau de aprofundamento das finanças de mercado, que depende, por sua vez, da intensidade dos processos de liberalização e desregulamentação financeiras em cada país.

16. Para uma análise detalhada da nova dinâmica macroeconômica nos países centrais, ver Aglietta (1995) e Coutinho e Belluzzo (1998).

17. Os fundos de pensão também passaram a apresentar um comportamento cada vez mais especulativo na medida em que a remuneração de seus gestores passou a depender de critérios de performance. A esse respeito, ver Freitas (1997).

18. O termo "assimetrias" foi tomado emprestado de Prebisch (1949), que enfatizou três tipos de assimetrias centro-periferia no âmbito do sistema capitalista mundial: tecnológicas/produtivas, macroeconômicas e financeiras.

19. Como ressaltam Belluzzo e Almeida (2002), no Treatise on Money Keynes já havia apontado a existência de uma hierarquia de moedas na análise dos diferentes graus de autonomia das políticas monetárias das economias devedoras e credoras no entre-guerras.

20. Bordo e Flandreau (2001) mostram que somente 25 países - dentre os quais, quatro países emergentes - têm capacidade de emitir dívida denominada em sua própria moeda no mercado financeiro internacional. Essa especificidade dos países "emergentes" também tem sido ressaltada por outros autores (ver Haussmann et al., 1999) segundo os quais esses países sofreriam de um "pecado original" que explicaria a sua incapacidade de se endividar externamente em sua própria moeda. Vale mencionar que em 2004 
alguns países emergentes, inclusive o Brasil, emitiram títulos denominados em suas próprias moedas (liquidáveis em dólares equivalentes à taxa de câmbio do dia do vencimento) no mercado financeiro internacional. Contudo, essas emissões são marginais e foram absorvidas, sobretudo, por investidores de perfil mais especulativo que apostavam na continuidade da tendência de desvalorização do dólar e na conseqüente valorização de algumas moedas.

21. Após o retorno dos fluxos de capitais voluntários para os países periféricos no início dos anos 90, proliferaram trabalhos empíricos sobre os determinantes desses fluxos, que distinguiram dois conjuntos de fatores: os fatores externos e os fatores internos/regionais. Enquanto os estudos realizados na primeira metade da década concluíram que os fatores externos conjunturais, principalmente a taxa de juros básica americana e a fase do ciclo econômico nos países centrais, tiveram um papel central na direção e no volume daqueles fluxos, estudos mais recentes relativizam a importância desses fatores e enfatizam o papel dos fatores externos estruturais - a globalização financeira - e a complementaridade entre os fatores externos - que determinariam o timing e o volume dos fluxos - e os internos — que condicionariam a sua distribuição regional (Jeanneau e Micu, 2002).

22. Os dados divulgados pelo BIS (2004) ilustram essa inserção marginal: em dezembro de 2003, os países centrais absorviam cerca de $90 \%$ do estoque de empréstimos bancários internacionais; e, em março de 2004, 94\% do estoque total de títulos negociados no mercado internacional de capitais haviam sido emitidos por residentes desses países.

23. Cálculos realizados pelo IMF (2003) identificaram um comportamento "sincronizado" entre os spreads desses papéis e aqueles dos títulos emitidos pelos "mercados emergentes".

24. Evidências nesse sentido são apresentadas, igualmente, pelo estudo de Dowers, Gomerz-Acebo; Masci (2000).

\section{REFERÊNCIAS BIBLIOGRÁFICAS}

AGLIETTA, M. (1995) Macroéconomie financière. 1. ed. Paris: La Découverte.

AKYÜZ, Y., CORNFORD, A. (1999) Capital Flows to Developing Countries and the Reform of the International Financial System. Genebra: United Nations Conference on Trade and Development. Unctad Discussion Papers, n. 143.

AKYÜZ, Y. (1992) On Financial Openess in Developing Countries, Genebra: Unctad. Trabalho não-publicado.

BAER, M. (1995) "Sistema financeiro internacional: oportunidades e restrições ao financiamento do desenvolvimento". Novos Estudos Cebrap, São Paulo, jul.

BELLUZZO, L. G. M. (1997) “Dinheiro e as transfigurações da riqueza”. In: M. C. Tavares e J. L. Fiori (orgs.), Poder e dinheiro: uma economia política da globalização. Petrópolis: Vozes, p. 151-193.

(1995) "O declínio de Bretton Woods e a emergência dos mercados globalizados". Economia e Sociedade, Campinas, n. 4., p. 11-20. 
BELLUZZO, L. G. M., ALMEIDA, J. S. G. (2002) Depois da queda: a economia brasileira da crise da dívida aos impasses do Real. Rio de Janeiro: Civilização Brasileira.

BIS (2004) Quartely Review. Basle: Bank for International Settlements, Jun.

BORDO, M. D., FLANDREAU, M. (2001) Core, Periphery, Exchange Regimes, and Globalization. Cambridge, Mass.: National Bureau of Economic Research. NBER Working Paper n. 8.584.

BRAGA, J. C. S. (1997) "Financeirização global: o padrão sistêmico de riqueza do capitalismo contemporâneo”. In: M. C. Tavares e J. L. Fiori (orgs.), Poder e dinheiro: uma economia política da globalização. Petrópolis: Vozes, p. 195-242.

BRUNHOFF, S. (1996) "L'instabilité monetaire internationale". In: F. Chesnais (coord.), La mondialisation financière: genèse, coût et enjeux. Paris: Syros, p. 33-57.

CARNEIRO, R. M. (1999) “Globalização financeira e inserção periférica”. Economia e Sociedade, Campinas, n. 13, p. 58-92.

CHESNAIS, F. (1997) La mondialisation du capital, nouvelle édition augmentée. Paris: Syros.

(1996) "Introduction générale". In: F. Chesnais (coord.), La mondialisation financière: genèse, coût et enjeux, Paris: Syros, p. 9-31.

CINTRA, M. A. (1997) As transformações na estrutura do sistema financeiro dos Estados Unidos: a montagem de um novo regime monetário-financeiro (1980-1995). Tese (Doutorado em Economia), Instituto de Economia, Universidade Estadual de Campinas, Campinas, nov.

COUTINHO, L., BELLUZZO, L. G. M. (1998) "Financeirização da riqueza, inflação de ativos e decisões de gasto em economias abertas". Economia e Sociedade, Campinas, n. 11, p. 137150.

(1996) “Desenvolvimento e estabilização sob finanças globalizadas". Economia e Sociedade, Campinas, n. 7, p. 129-154.

COLANDER, D., HOLT, R., ROSSER, B. (2003) The Changing Face of Mainstream Economics. Department of Economics, Middleburry College, Middlebury, Vermont. Discussion Paper n. 03-27.

DOWERS, K. F., GOMEZ-ACEBO, MASCI, P. (2000) "Making capital markets viable in Latin America”. Infrastructure and Financial Markets Review, v. 3. Washington: International Monetary Fund, Dec.

EICHENGREEN, B. (1996) Globalizing Capital: a history of the International Monetary System. Princeton: Princeton University Press.

EATWELL, J., TAYLOR, L. (2000) Global Finance at Risk: the case for international regulation. Nova York: The New Press.

FARHI, M. (1999) “Derivativos financeiros: hedge, especulação e arbitragem”. Economia e Sociedade, Campinas, n. 13, p. 93-114.

(1998) O futuro no presente: um estudo dos mercados de derivativos financeiros. Tese (Doutorado em Economia), Instituto de Economia da Universidade Estadual de Campinas, Campinas. 
FELIX, D. (1994) “Mobilité financière internationale: effets déstabilisateurs et régulation”. Revue Tiers Monde, t. XXXV, n. 139.

FREITAS, M. C. F. (1997) Concurrence bancaire, speculation et instabilité financière: une lecture hétérodoxe de l'évolution récente du système financier internacional. Tese (Doutorado em Economia), Université de Paris XIII, Paris.

FREITAS, M. C. P., PRATES, D. M. (2003) "Sistema financeiro e desenvolvimento: as restrições das novas regras do comitê da Basiléia sobre os países periféricos”. In: J. C. Ferraz, M. Crocco e L. A. Elias, Liberalização econômica e desenvolvimento: modelos, políticas e restrições. São Paulo: Futura.

GUTTMANN, R. (1996) “Les mutations du capital financier”. In: F. Chesnais (coord.), La mondialisation financière: genèse, coût et enjeux. Paris: Syros, p. 59-96.

(1993) International monetary reforme. Papier présenté dans un séminaire au CEDI/ Université Paris-Nord, June. Trabalho não publicado.

GRIFFITH-JONES, S. (1995) “Globalización de los mercados financeiros y el impacto de los flujos hacia los países en desarrollo: nuevos desafíos para la regulación”. Pensamiento Iberoamericano, Madri, n. 27.

HAUSMANN, R. et al. (1999) Financial Turmoil and the Crises of Exchange Rate Regimes. Washington: Banco Interamericano de Desarrollo. IADB Working Paper n. 400.

IMF (2003) Global financial stability. Washington DC: International Monetary Fund, Mars.

HELLEINER, E. (1994) States and the Reemergence of Global Finance, from Bretton Woods to the 1990's. Ithaca e Londres: Cornell University Press.

JEANNEAU, S., MICU, M. (2002) Determinants of international bank lending to emerging market countries. Basle: Bank of International Settlement. BIS Working Papers n. 112.

KEYNES, J. M. (1980) The Collected Writings of John Maynard Keynes, v. XXV, activities 194044: Shaping the Post-War World, the Clearing Union, D. Moggridge (ed.). Londres: Macmillan.

(1964) The General Theory of Employment, Interest and Money. 14. ed. Londres: MacMillan, (1. ed., 1936).

KREGEL, J. (1996) "Riscos e implicações da globalização sobre a autonomia das políticas nacionais". Economia e Sociedade, Campinas, n. 7, p. 29-49.

KRUGMAN, P. (1979) “A model of balance of payments crises". Journal of Money, Credit and Banking, v. 11, n. 3, Aug., p. 311-325.

MEDEIROS, C. A., SERRANO, F. (1999) "Padrões monetários internacionais e crescimento". In: J. L. Fiori (org.), Estados e moedas no desenvolvimento das nações. Petrópolis: Vozes, p. $119-154$.

MIRANDA, J. C. (1998) “A dinâmica financeira da crise asiática”. Revista Política Externa, Rio de Janeiro, v. 6, n. 4, p. 130-150.

(1995) “Algumas questões de economia internacional contemporânea". Indicadores FEE, Porto Alegre, v. 23, p. 184-199 (Câmbio: o dilema da estabilização no México, na Argentina e no Brasil). 
OCAMPO, J. A. (2001) International Asymmetries and the Design of the International Financial System. Santiago, Chile: Cepal, abr. (Series Temas de Coyuntura n. 15).

ORLÉAN, A. (1999) Le pouvoir de la finance. Paris: Editions Odile Jacob.

PLIHON, D. (1996) “Desequilibres mondiaux et instabilité financière: les responsabilité des politiques libérales”. In: F. Chesnais (coord.), La mondialisation financière: genèse, coût et enjeux. Paris: Syros, p. 97-141.

PREBISCH, R. (1949) Economic Survey of Latin America. Nova York: United Nations, 1950.

SERFATI, C. (1996) "Le rôle actif des groupes à dominance industrielle dans la financiarisation de l'economie”. In: F. Chesnais (coord.), La mondialisation financière: genèse, coût et enjeux, Paris: Syros, p. 143-183.

SERRANO, F. (2002) “Do ouro imóvel ao dólar flexível”. Economia e Sociedade, v. 11, n. 1., p. 237-254.

SHUMEISTER, S. (2000) "Globalization without global money: the double role of the dollar as national currency and world money". Journal of Post-Keynesian Economics, v. 22, n. 3, spring, p. 365-395.

STUDART, R. (2003) "A integração de parceiros desiguais: os efeitos desestabilizadores da liberalização financeira e a internacionalização das economias latino-americanas". In: J. C. Ferraz, M. Crocco e L. A. Elias, Liberalização econômica e desenvolvimento: modelos, políticas e restrições. São Paulo: Futura.

STRANGE, S. (1986) Casino Capitalism. Oxford: Basil Blackwell.

TAYLOR, L. (1998) Lax Public Sector, Desestabilizing Private Sector. Nova York: Center for Economic Analysis, New School for Social Research, (Working Paper Series III).

TAVARES, M. C. (1997) “A retomada da hegemonia americana”. In: M. C. Tavares e J. L. Fiori (orgs.), Poder e dinheiro: uma economia política da globalização. Petrópolis: Vozes, p. 27-54.

—_ MELIN, L. E. (1997) "Pós-escrito 1997: a reafirmação da hegemonia americana". In: M. C. Tavares e J. L. Fiori (orgs.), Poder e dinheiro: uma economia política da globalização. Petrópolis: Vozes, p. 55-86.

TEIXEIRA, A. (2000) "O Império contra-ataca: notas sobre os fundamentos da atual dominação norte-americana”. Economia e Sociedade, Campinas, n. 15, dez., p. 1-13.

TURNER, P. (1991) Capital Flows in the 1980's: a survey of major trends. Basle: Bank for International Settlements. BIS Economic Papers n. 44. 